\title{
ENTRE LA DIPUTACIÓN DEL GENERAL DE CATALUÑA Y LA CÁMARA APOSTÓLICA: LA TRAYECTORIA DEL COLECTOR BERNAT VALLÈS (1365-1389)*
}

\author{
POR \\ ESTHER TELLO HERNÁNDEZ ${ }^{1}$ \\ Universitat de València
}

\section{RESUMEN}

Bernat Vallès fue un miembro de la clerecía barcelonesa de la segunda mitad del siglo XIV y uno de los considerados «primeros presidentes» de la Generalitat de Cataluña. Fue nombrado diputado eclesiástico en las Cortes de Tortosa de 1365 y, en ese mismo año, se le documenta ya en relación con la Cámara Apostólica de Aviñón. Centrándonos en su perfil polifacético y empleando documentación del Archivo de la Corona de Aragón y del Archivo Apostólico Vaticano, nos interesa analizar la gestión fiscal y financiera de este personaje en relación con la fiscalidad regia y pontificia. Todo ello, en un periodo significativo para la consolidación de la fiscalidad general en la Corona de Aragón y la fiscalidad pontificia de Aviñón, y en un momento transcendental respecto a las relaciones monarquía-papado.

PALABRAS CLAVE: Corona de Aragón; Baja Edad Media; fiscalidad pontificia; Diputación del General de Cataluña; décima pontificia; subsidio.

\section{AMID THE COUNCIL OF THE GENERAL OF CATALONIA AND THE APOSTOLIC CHAMBER: THE CARRIER OF THE COLLECTOR BERNAT VALLÈS (1365-1389)}

\begin{abstract}
Bernat Vallès was a member of the clergy of Barcelona in the second half of the fourteenth century, often considered one of the first 'presidents' of the Generalitat of Catalonia. He was appointed ecclesiastical representative of the Generalitat at the Cortes of Tortosa of 1365, and his relations with the Apostolic Chamber of Avignon is documented in the same year. By focusing in his plural profile and by turning to records in the Archive of the Crown of Aragon and the Vatican Archives, we analyse the fiscal and financial management of this person in relation to real and papal taxation. This is studied in a meaningful period in the consolidation of general taxation in the Crown of Aragon and Avignon Papacy, and in a key moment of the relations between monarchs and papacy.

KEY WORDS: Crown of Aragon; Late Middle Ages; pontifical taxation; Deputation of the General of Catalonia; pontifical tithes; papal subsidy.

Cómo CITAR ESTE ARTículo / CitATION: Tello Hernández, Esther. 2021. «Entre la Diputación del General de Cataluña y la Cámara Apostólica: la trayectoria del colector Bernat Vallès (1365-1389)». Hispania Sacra LXXIII, 148: 325-338. https://doi.org/10.3989/ hs.2021.025
\end{abstract}

Recibido/Received 02-04-2020

Aceptado/Accepted 13-07-2020

\begin{abstract}
Contratada Juan de la Cierva formación en la Universitat de València (ref. JFCl-2017-32998). Este trabajo ha sido posible gracias a un contrato postdoctoral en la Escuela Española de Historia y Arqueología en Roma (EEHAR-CSIC) que ha permitido llevar a cabo las investigaciones pertinentes en el Archivo Apostólico Vaticano. En última instancia, este estudio se enmarca en los grupos de investigación Desigualdad económica y movilidad social en la Europa Mediterránea, siglos XIIIXVI (ref. Prometeo2019/072) y Renda feudal i fiscalidad a la Catalunya Baix-Medieval (ref. 2017-SGR-1068), y se ha desarrollado en el marco
\end{abstract}

\begin{abstract}
de los proyectos de investigación del Ministerio de Ciencia, Innovación y Universidades ¿Crecimiento sin desarrollo? Distribución de la riqueza, movilidad social y acción política en la Europa Mediterránea (siglos XIII-XV) (ref. PGC2018-099275) de la Universitat de València y La desigualdad económica en las ciudades catalanas y mallorquinas durante la baja Edad Media (ref. PGC2018-100979-B-C22) de la Institución Milá y Fontanals de Investigación en Humanidades (IMF-CSIC. Barcelona). 1 esther.tello@uv.es / ORCID iD: https://orcid.org/0000-00025985-3791
\end{abstract}




\section{INTRODUCCIÓN}

Bernat Vallès fue un miembro de la clerecía barcelonesa de la segunda mitad del siglo XIV y uno de los considerados «primeros presidentes» de la Generalitat de Cataluña. Licenciado en leyes, canónigo de Barcelona y rector de Santa Maria de Badalona (Barcelona) y de Sant Pere Pescador (Girona), fue nombrado diputado eclesiástico de la incipiente Diputación del General en las Cortes de Tortosa de 1365. Ese mismo año, se le documenta como subcolector de la décima pontificia en el obispado de Barcelona. Y, diez años después en el mismo obispado, desempeñó el cargo de subcolector de la Cámara Apostólica de Aviñón, principal órgano fiscal y financiero del papado. ${ }^{2}$

Centrándonos en su perfil polifacético y empleando documentación procedente del Archivo de la Corona de Aragón y del Archivo Apostólico Vaticano, nos interesa analizar la gestión fiscal y financiera de este personaje en torno al donativo de las Cortes de Tortosa de 1365 y su labor simultanea como subcolector de la recaudación de la décima pontificia en el obispado de Barcelona. Sin duda, la experiencia adquirida durante estos años influyó para que, una década después, fuese designado subcolector de la Cámara Apostólica y gestionase diversas exacciones pontificias. Las funciones que desempeñó este personaje durante buena parte de su carrera nos ayudan a comprender la trayectoria dual y el contexto de este eclesiástico que, durante poco más de una década, tuvo un papel muy activo tanto por lo que respecta a la gestión de las finanzas regias, como eclesiásticas y pontificias. ${ }^{3}$

Para llevar a cabo este estudio, me dispongo, en primer lugar, a contextualizar la figura de Bernat Vallès en relación con el donativo de las Cortes de Tortosa. Como decíamos, su presencia en dicha asamblea y su papel como recaudador del donativo le debió servir de carta de presentación para convertirse en subcolector de la décima de 1365 en el obispado de Barcelona, aspecto que trato en segundo lugar. Asimismo, más allá de su labor vinculada a la recaudación de la décima, Vallès continuó su cursus honorum siempre en relación con la administración fiscal y financiera eclesiástica.

Abreviaturas utilizadas: $A C A=A r c h i v o$ de la Corona de Ara-

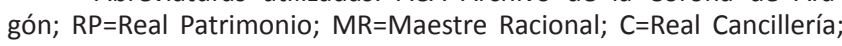
$\mathrm{AAV}=$ Archivo Apostólico Vaticano; Coll=Colectoría. Las cantidades monetarias se expresan en libras, sueldos y dineros barceloneses (I., s. y d.) y florines de Aragón (fl.). Agradezco a Manuel Sánchez y a Jordi Morelló la referencia al registro de Bernat Vallès conservado en el Archivo Apostólico Vaticano y sus orientaciones a la hora de estudiar esta fuente. Como síntesis de la trayectoria general de Bernat Vallès, sobre todo por lo que respecta a su papel como diputado del brazo eclesiástico en las Cortes de Tortosa, véanse los estudios de Ferrer i Mallol 1984 y 2003.

En los últimos años han sido numerosos los estudiosos que se han dedicado a investigar la movilidad social del clero y su ascenso político: Carocci y De Vicentis 2017; VV. AA 2007; Jamme y Poncet 2005; Vones-Liebenstein 2005; Nieto Soria y Díaz Ibáñez 2001. Entre todos estos puntos de vista, hace tiempo se señaló la importancia que tiene la fiscalidad y finanzas como vía de estudio para la movilidad y promoción social de este grupo, tanto en el entorno de la hacienda regia como pontificia: Morelló Baget 2012, 2013a; Le Roux 2011; Greiner 1953; Glénisson 1947, entre otros. De hecho, los artículos de L. Greiner y J. Glénisson enlazan directamente con la última parte del presente artículo, ya que estudian la actuación de dos colectores apostólicos fundamentales para conocer el funcionamiento de la hacienda pontificia y la colectoría de Aragón durante el último tercio del siglo XIV: Bertrand du Mazel y Pere Borrer.
En tercer lugar, me refiero a cómo, diez años después de las Cortes de Tortosa, lo documentamos como colector de la Cámara Apostólica recaudando varias exacciones pontificias, siempre, eso sí, en el obispado barcelonés.

Previamente a entrar de lleno en el artículo, debemos advertir que no conocemos bien los inicios de su carrera eclesiástica. Suponemos que sus orígenes se localizan entre Sant Celoní y el Alt Empordà. ${ }^{4}$ Como veremos, Vallès no fue un miembro de la alta jerarquía eclesiástica, aunque sí estaba muy ligado a la mensa barcelonesa. Pese a ello, sí hemos podido reconstruir de forma fidedigna las labores que desempeñó durante estos años en las esferas eclesiástica, regia y pontificia.

\section{Bernat Vallès como diputado del General de CATALuña (1365-1367)}

La Diputación del General fue un organismo que surgió con el propósito de recaudar los donativos aprobados por las Cortes. En principio, esta comisión tuvo un carácter temporal que, poco a poco, se convirtió en permanente. Tal como señalan Manuel Sánchez y Pere Orti, los años de la guerra contra Castilla (1356-1367) y, en especial, el intervalo comprendido entre 1359 y 1365 fueron cruciales para la consolidación de este organismo o comisión que estaba encabezado por representantes de todos los brazos. ${ }^{5}$

En este contexto, con la ruptura de la paz de Deza-Terrer con Castilla en 1362, el Ceremonioso buscó reunir rápidamente Cortes generales. En noviembre de 1362, en las Cortes generales de Monzón, los brazos de los tres territorios peninsulares concedieron un donativo a recaudar vía fogaje. En la misma asamblea se aprobó un nuevo impuesto indirecto, las generalidades, que gravaba la producción y venta de paños, así como la importación y exportación de algunos productos con el fin de nutrir las arcas del rey durante esta segunda fase de la Guerra de los Dos Pedros. ${ }^{6}$ Durante los meses siguientes, el monarca continuó buscando tan ansiada financiación y reunió una asamblea en Zaragoza e intentó hacer lo propio en Barcelona. Finalmente, el rey convocó a las Cortes catalanas en Tortosa que terminaron por trasladarse a Lleida y Barcelona entre 1364 y finales de 1365. Tal como señala Manuel Sánchez, era la primera vez que el principado estaba sometido a una presión fiscal tan elevada y, además, los procedimientos fiscales y financieros empleados para recaudar el donativo eran muy novedosos. ${ }^{7}$

Por lo que aquí nos interesa, en las Cortes de BarcelonaLleida-Tortosa se aprobó uno de los donativos más cuantiosos de los concedidos al rey por el principado, que ascendía a 650.000 libras a pagar en dos años. Más allá de este hecho, estudiado en profundidad por Manuel Sánchez y Pere Orti, nos interesa su peculiar forma de recaudación. Como

$4 \quad$ Más allá de las obras ya citadas, remito al estudio de Josep Maria Abril quien vincula los orígenes de su familia a la villa de Sant Celoni y la carrera de Bernat Vallès a la rectoría de Sant Martí de Pertegàs (Abril i López 1995, 90).

Entre muchas referencias posibles para este periodo, remito a Sánchez Martínez 2011; Ferrer i Mallol 2004, 2009; Ferrer i Mallol y Roig Rosich 2011; Sánchez Martínez y Orti Gost 1997, XVI-XXI.

6 Como veremos, la transcendencia que tuvieron en materia fiscal y financiera las Cortes generales de Monzón está fuera de toda duda: Sánchez, Furió y Sesma 2008, 120-124.

Sánchez Martínez 2005. 
es sabido, una parte se obtendría a través de los impuestos indirectos de las generalidades apenas mencionados; otra parte se recaudaría a través del impuesto directo (fogaje); y otra parte del donativo, 50.000 I., sería cobrado a través de la emisión de deuda pública cargada sobre los derechos de las generalidades, así como, en menor medida, sobre los ingresos de la ceca de Perpiñán y la gabela de la sal. ${ }^{8}$ En última instancia, el donativo se debía depositar en una taula de canvi o banca privada con el fin de gestionar de una manera eficiente los ingresos y gastos. Sin embargo, ante la lentitud de las recaudaciones ordinarias, el rey recurrió a financieros privados para que le adelantasen el dinero del donativo otorgado en las Cortes. Como consecuencia de ello, el banquero Berenguer Bertran fue designado recaudador del donativo y supervisó la colecta del mismo, junto con otros banqueros de su entorno como Eimeric Dusai y Jaume de Gualbes, principales agentes financieros del rey del momento, tal como pusieron de relevancia Albert Reixach y Jordi Morelló. ${ }^{9}$

Como era costumbre, el donativo tenía que ser percibido y gestionado por una comisión creada por las Cortes, el germen directo de la Diputación del General. En particular, quince miembros pertenecientes a los tres brazos componían un complejo organigrama administrativo de auditores y oficiales, al frente de los cuales estaban tres diputados principales, uno por cada brazo. Estos tres diputados debían residir en Barcelona y disponían de amplias competencias para administrar el donativo y llevar a cabo el procedimiento de venta de deuda pública durante los tres años posteriores. Así, en los capítulos de las Cortes de Barcelona, aprobados en diciembre de 1365 , se nombraron diputados residentes a Bernat Vallès (por el brazo eclesiástico), a Bernat Sestorres (por el brazo de caballeros) y a Pere Bussot (por el brazo de las ciudades). ${ }^{10}$

Así, Bernat Vallès tuvo un papel predominante como diputado del brazo eclesiástico durante este trienio. Ejercer un control sobre el donativo y estar al frente de la venta de deuda pública, le permitió entrar en contacto con otras esferas de la fiscalidad y finanzas regias. Ahora bien, que sea considerado uno de los "primeros presidentes» de la Generalitat de Cataluña es debido, exclusivamente, a una preeminencia honorífica sobre los otros dos diputados principales, pues no debemos olvidar que se trataba de un órgano colegiado encargado de gestionar los donativos otorgados en

8 Los capítulos de donativo de estas Cortes están transcritos en Sánchez Martínez y Orti Gost 1997, doc. XX (2), item 15. Para un estudio más detallado de este episodio, remito a Orti Gost 1999, 765; Sánchez Martínez 2009, 223.

Sánchez Martínez y Orti Gost 1997: doc. XX (2), item 15; Sánchez Martínez 2009, 223-225. Por todo el principado actuaron un conjunto de cambistas que colaboraron en el anticipo y recaudación de parte del donativo que se debía obtener vía fogaje. Para los casos de Girona y Tarragona, véanse respectivamente: Reixach Sala 2012; Morelló Baget 2001, 180-182.

10 Sánchez Martínez y Orti Gost 1997, doc. XX (2), items 22 y 43. Como diputado del brazo eclesiástico también fue nombrado Berenguer Despujol, canónigo de Vic; como diputado del brazo militar, Bernat Alemany de Orriols; $y$, como diputados del brazo de las ciudades y villas reales, Pere Desplà, ciudadano de Barcelona, y Ermengau Martí, burgués de Perpiñán (Ferrer i Mallol 2005, 528-532; Ferrer i Mallol y Roig Rosich 2011, 19-45). Aparte de las obras señaladas, para las competencias que fueron adquiriendo progresivamente estos diputados en torno a sus atribuciones fiscales, más allá de las administrativas, véase también el estudio de Ripoll Sastre 2018, 18-27. las asambleas, tal como explican M. Sánchez o M.T. Ferrer. De hecho, durante la época bajomedieval, los considerados primeros diputados o diputados a la cabeza de la Generalitat eran eclesiásticos que, debido a su estatus con respecto a los demás diputados del brazo de caballeros y del ciudadano, gozaban de una mayor jerarquía. Además, tampoco podemos olvidar que, al menos durante las primeras décadas en las que estuvo vigente esta institución, la función de los diputados era puramente técnica y temporal, y hasta el siglo XV no comenzó a alcanzar un prestigio político más acreditado a la par de que consolidó su régimen jurídico. ${ }^{11}$

Como colofón a este apartado, podemos indicar que los perfiles de los diputados eclesiásticos de estos primeros años no siempre tuvieron unas características similares. Poco antes y después de Vallès, ocuparon los cargos de diputado varios obispos y dignidades religiosas del principado. Berenguer de Cruïlles, obispo de Girona entre 1349 y 1362, fue nombrado diputado en las Cortes de Cervera de 1359 y estuvo al frente de la gestión impositiva entre 1359 y $1362 .{ }^{12}$ Por su parte, Romeu Sescomes, mitrado de Lleida, fue designado diputado en las Cortes generales de Monzón de 1362 y desempeñó su cargo entre 1363 y $1364 .{ }^{13}$ Sin pretender hacer una sociología conjunta o prosopografía de los diputados, sí que debemos destacar que muchos de ellos estuvieron vinculados a otras empresas de la monarquía y del papado y jugaron un papel muy activo en las finanzas regias y pontificias. De hecho, unas décadas después, no es extraño documentar a algunos de estos diputados gestionando y ocupando otros cargos en la curia. A finales del siglo XIV, Arnau Descolomer, que había sido diputado entre 1384 y 1389, formó parte activa de las personas de confianza del papa Benedicto XIII; lo mismo que Alfonso de Tous, ya a comienzos del siglo XV. También el eclesiástico Domingo Ram ocupó el cargo de diputado entre 1428 y 1431 y ya había obtenido la proclamación cardenalicia en 1423; Ram, además, había sido anteriormente obispo de Huesca y Lleida y fue arzobispo de Tarragona en la década de $1430 .{ }^{14}$

\section{BERNAT VALLÈS, LA DÉCIMA DE 1365 Y SU TRAYECTORIA EN LA CLERECÍA BARCELONESA}

Unos meses después de las Cortes de Tortosa y mientras la asamblea estaba reunida nuevamente en Barcelona, el

11 Para el asunto de los diputados y la evolución de la institución entre los siglos XIV y XV, véanse: Riera i Melis 2011; Serra i Puig 2011; Montagut i Estragués 1996, 95-118. En cuanto al ordenamiento jurídico de la Diputación del General en el siglo XV, consúltese, asimismo: Ripoll Sastre $2013,559-560$ y 571-572, así como los estudios más actuales de Torra 2020 para el periodo justo posterior.

12 De Puig i Oliver y Marquès Planagumà 2007 y 2008.

13 Solé i Sabaté 2003, con especial mención al artículo de Ferrer (2003, 57-60).

${ }_{14}$ La figura del polifacético Domingo de Ram es bastante conocida. Hijo de un consejero cercano a Pedro IV, a mediados de la década de 1390 fue prior de la colegiata de Alcañiz, primero, y de la catedral de Zaragoza, después. En 1410 fue nombrado obispo de Huesca por el papa Benedicto XIII y participó en el Compromiso de Caspe, donde fue elegido rey Fernando de Antequera. Unos años después, en 1415, fue traspasado a la mitra de Lleida y en 1434, ya como arzobispo de Tarragona, fue embajador de Alfonso $\mathrm{V}$ en el concilio de Basilea (Eubel 1913, 34). Sea como sea, para profundizar en la mayoría de estos perfiles remito como estudio de referencia a la obra ya mencionada de Solé i Sabaté 2003 
27 de agosto de 1365 el papa Urbano V (1362-1370) otorgó una décima bienal a recaudar en la Corona de Aragón. La décima era un impuesto extraordinario promulgado por el papa que surgió a finales del siglo XII con el propósito inicial de financiar las cruzadas a Tierra Santa, gravándose para ello los beneficios eclesiásticos con un porcentaje variable -en este caso el $10 \%$ - de la renta anual neta a lo largo de un año. ${ }^{15}$ Sin embargo, desde mediados del siglo XIV, los papas concedieron una y otra vez parte o la totalidad de la décima recaudada en la Corona a los monarcas aragoneses para que hiciesen frente a las revueltas de Cerdeña. Por lo que aquí nos interesa, cada vez que se promulgaba una décima se ponía en marcha una administración propia formada por colectores y subcolectores eclesiásticos que, con apoyo de los oficiales reales, se encargaban de cobrar y gestionar el impuesto. En última instancia, estos subcolectores eran también los responsables de rendir cuentas de su ejercicio ante el maestre racional, principal oficial financiero del monarca al que todos los administradores de rentas y tributos regios debían presentar sus cuentas. ${ }^{16}$

En particular, la décima de 1365 se recaudó durante dos anualidades, desde febrero de 1366 hasta junio de $1367 .{ }^{17}$ A la cabeza de esta administración se situaron los colectores generales nombrados por el papa en la bula de concesión: el obispo de Urgel, Pedro Martínez de Luna; el arzobispo de Tarragona, Pere de Clasquerí; y el obispo de Barcelona, Guillem de Torrelles. Sin embargo, la recaudación efectiva de la exacción recaía en manos de los subcolectores diocesanos, que fueron nombrados el 24 de octubre de $1365 .{ }^{18}$ Estos eclesiásticos eran designados por los colectores generales unos meses después de otorgarse la bula y desempeñaban sus labores por una o varias diócesis. De hecho, normalmente eran canónigos diocesanos, buenos conocedores del terreno y con una capacidad destacada para gestionar el impuesto. En el caso del obispado de Barcelona, en un primer momento se designó como subcolector al recién elegido obispo de Urgell, Pedro de Luna (1365-1370), pero, poco tiempo después fue relevado de la misión justificando que "fos occupat en diversses altres negocis per rahó de la sua dignitat e en la cullita de la dita dècima entendre no pogués, per çò confiant de la indústria e leyaltat de vosaltres, los dits Bernat Vallès e en Bernat d'Esplugues, comanà a vosaltres la exacció della cullita della dita dècima en la ciutat e en lo bisbat de Barchinona ${ }^{19} .{ }^{19}$ Así, finalmente, fueron designados como subcolectores en el obispado barcelonés estos dos canónigos diocesanos, Bernat Vallès y Bernat d’Esplugues. ${ }^{20}$

15 Sobre este impuesto en general, véanse: Lunt 1965, 71-77; Mollat y Samaran 1905, 11-68.

16 Durante la década de 1360 , el papa Urbano V (1362-1370) otorgó dos décimas bienales; una en 1363 y otra en 1365, la que aquí nos interesa. Para contextualizar la concesión de décimas con los ciclos fiscales de la Corona de Aragón durante la década de 1360, acúdase a Tello Hernández 2020a; Morelló Baget 2017, 653-656.

17 Los dos volúmenes de la recaudación de la décima pontificia de 1365 en el obispado de Barcelona se conservan en ACA, RP, reg. 1810 y 1811.

18 Así aparece en la bula pontificia que se transcribe al comienzo del registro correspondiente y en la carta de nombramiento de los subcolectores: ACA, RP, reg. 1810, sin fol.

19 ACA, RP, MR, albaranes, reg. 645, ff. 182r-183v (Barcelona 12/08/1368).

20 ACA, RP, reg. 1810, sin fol. Como subcolector del obispado de Vic fue designado el canónigo Berenguer Despujol, que también fue,
A grandes rasgos, podemos decir que la gestión de estos subcolectores en relación con la recaudación de la décima resultó más o menos eficaz y que, al menos en el obispado de Barcelona, parece ser que cumplió las expectativas del monarca. Gracias a los libros contables que recogen los ingresos y gastos y a los albaranes testimoniales emitidos como resultado de la auditoria final de cuentas, sabemos que Bernat Vallès recaudó en la diócesis unos 68.733 s., cantidad más o menos esperada y que era similar a las colectas de años anteriores. ${ }^{21}$ Las cuentas finales se presentaron ante el racional en agosto de 1368, poco más de un año después de finalizar la recaudación ordinaria. ${ }^{22}$

Parte de su eficacia también estuvo vinculada a la gestión financiera del impuesto. $Y$ he aquí un punto en común con el apartado anterior. A través de una lectura atenta de los libros de cuentas, podemos decir que buena parte de los ingresos estaban asignados al ya citado banquero Berenguer Bertran, así como a Jaume de Gualbes y Eimeric Dusai. No nos debe extrañar que fueran recibidores de la décima «per especial assignació per lo senyor rey a els feta per rahó d'algunes quantitats de diners que havien prestades al dit senyor rey", ${ }^{23}$ ya que, recordemos, estos tres personajes actuaron como prestamistas de parte de las cantidades acordadas en el donativo de las Cortes de Tortosa y que la taula de canvi de Bertran se situaba a la cabeza del juego financiero. Además, Berenguer Bertran también había prestado dinero al monarca para el pago del tributo que anualmente debía librarse a la Santa Sede por la tenencia en feudo de la isla de Cerdeña, razón por la cual le fueron asignados parte de los ingresos de la décima. ${ }^{24}$ En particular, a través de un reconocimiento de deuda de enero de 1366, el baile general de Cataluña, Pere Sacosta, y el tesorero, Berenguer de Relat, asignaron a Bertran 11.000 florines a recaudar en parte de las décimas «dels diners qui a nostras mans pervendrien per rahó de la dita dècima». ${ }^{25}$ En total, según las cuentas del subcolector Ber-

recordemos, diputado en las Cortes de Barcelona apenas mencionadas (ACA, RP, reg. 1816). Despujol, además, ya había asistido a las Cortes de Cervera de 1359 y había sido vicario general del obispo de Valencia en la década de 1350.

21 Los ingresos totales de la décima bienal de 1363 en el obispado ascendieron a 69.470 s. (ACA, RP, MR, albaranes, reg. 645, ff. $258 \mathrm{v}$ 259v. Barcelona. 14/05/1369) y los de la bienal de 1354 supusieron una cantidad algo menor, 64.996 s. (ACA, RP, MR, albaranes, reg. 644, ff. 27v-29r. Barcelona. 25/07/1362).

22 ACA, RP, MR, albaranes, reg. 645, ff. 182r-183v (Barcelona. $12 / 08 / 1368)$. En general, podemos indicar que la recaudación en el resto de los obispados de la Corona de Aragón también se llevó a cabo sin muchos problemas. De hecho, de la lectura atenta de los registros de albaranes, se deduce que la mayoría de los subcolectores presentaron las cuentas ante el racional entre uno y tres años después de la última paga.

${ }_{23}$ ACA, RP, MR, albaranes, reg. 645, f. 183v.

24 Aunque no podemos entrar de lleno en esta cuestión, por la enfeudación de las islas de Cerdeña y Córcega el rey debía pagar anualmente un censo o tributo de 2.000 marcos de plata al papado $y$, en buena medida, este asunto estaba muy presente cuando se recaudaba una décima: Tello Hernández 2020b; Reixach 2012, 57. Sobre el problema del pago del censo por Cerdeña y Córcega durante estos años, véanse las continuas referencias para conseguir aplazamientos y deducciones de pago en: AAV, reg. aven., 164, f. 333r. 13/12/1366 (cit. en Laurent 1954-1985, doc. 20147).

25 ACA, RP, reg. 1811, f. 101r 
nat Vallès, unos $57.000 \mathrm{~s}$. del total de la colecta fueron a parar al banquero. ${ }^{26}$

Tiempo después, cuando había concluido tanto su labor como diputado eclesiástico de la incipiente Diputación del General, como el de subcolector de la décima, documentamos a Vallès participando activamente en diversos asuntos eclesiásticos, siempre relacionados con la gestión y administración fiscal y financiera. Por ejemplo, Vallès asistió al concilio de Tarragona celebrado en 1369 y, parece ser, estuvo a la cabeza de la recaudación de una derrama o talla que se aprobó en dicha reunión y que afectó a la archidiócesis tarraconense. Tal como indica Jordi Morelló, nuestro personaje, junto con otros eclesiásticos, debía auditar las cuentas de una recaudación ya concluida y establecer una nueva derrama en el obispado barcelonés. ${ }^{27}$ Poco después, Vallès asistió como miembro del brazo eclesiástico a las Cortes de Tarragona y Montblanc de $1370-1371 .{ }^{28}$ En este caso formó parte de una comisión que debía determinar las deducciones aplicadas en la diócesis de Barcelona a los eclesiásticos a raíz de la recaudación de las generalidades en las que se vio envuelto este estamento. ${ }^{29}$ Finalmente, desde 1375 hasta 1378 fue procurador y administrador de la Pia Almoina de Barcelona y, unos años más tarde, parece ser que actuó como auditor de las cuentas de dicha institución. ${ }^{30}$

En definitiva, su perfil como eclesiástico conocedor de la diócesis barcelonesa y con una amplia trayectoria en cuanto a materia fiscal y financiera, nos ayuda a comprender que también ocupase el cargo de subcolector de la Cámara Apostólica en la diócesis de Barcelona unos años después.

\section{La colectoría de Pere BorRer y la labor de Bernat Vallès COMO SUBCOLECTOR}

El 3 de octubre de 1374, Pere Borrer, canónigo de Barcelona y capellán del papa Gregorio XI, fue nombrado colector apostólico en las provincias de Tarragona, Zaragoza y Mallorca con el fin de recaudar un sinfín de rentas pontificias en los obispados de la Corona. Debemos advertir, sin embargo, que cada renta o tributo percibido por el papado a través de los colectores tenía una importancia desigual dentro de los ingresos totales de las arcas pontificias, a la vez que también difería en cuanto a su gestión. Historiográficamente, muchos autores han diferenciado entre aquellas exacciones que se pagaban directamente a la curia y aquellas que eran percibidas a través de los colectores; estas últimas serían las rentas y tributos recaudadas en territorio de la Corona a tra-

26 La suma total correspondía tanto a las cantidades debidas anteriormente, como al pago de los intereses adquiridos: ACA, RP, reg. 1811 , f. 101 r (15.000 s.); f. $101 v$ (14.000 s. y 1.000 s.), 102 r, (12.000 s. y 9.795 s.). Con todo, debemos tener en cuenta que, en este momento, también entró en juego la taula de los banqueros Emeric Dusai y Jaume de Gualbes, quienes recibieron gran parte de los ingresos de las décimas en su banca privada para satisfacer pagos debidos por el monarca a terceros y realizar las dites $u$ órdenes de pago correspondientes (ACA, RP, TR, reg. 356, f. 3v). En esta colecta, por ejemplo, el tándem Dusai-Gualbes recibió 5.290 s. (ACA, RP, reg. 1811, f. 103r).

27 Morelló Baget 2018, 196-197.

28 Cortes de Cataluña 1899, 116.

29 Para una mayor información sobre esta transcendente cuestión que afectó a los eclesiásticos en la década de 1370, aunque queda lejos de este estudio, remito a Morelló Baget 2013b.

30 Cf. Franklin 2017; López Pizcueta 1999; Baucells i Reig 1973, vés de estos eclesiásticos: anatas, procuraciones, espolios, vacantes, así como impuestos como la décima o subsidios, tal como veremos a continuación. ${ }^{31}$

Cuando el papa Gregorio XI nombró a Pere Borrer como nuncio y colector en la colectoría de Aragón se estableció que él mismo podría designar a quien considerase oportuno para que, durante dos años, percibiese parte de estas rentas y derechos de la Cámara Apostólica en los diferentes obispados. De este modo, debido también a que Borrer no podía hacerse cargo del grueso de la recaudación en el obispado de Barcelona, nombró, en mayo de 1375, a Bernat Vallès como lugarteniente y subcolector de la Cámara Apostólica. ${ }^{32}$

La labor de Vallès la conocemos gracias a la documentación conservada en el Archivo Apostólico Vaticano. En particular, según un registro contable, tres fueron los cometidos principales a los que debió hacer frente nuestro personaje durante estos años. En primera instancia, fue el encargado de percibir varias exacciones pontificias de carácter heterogéneo (anatas, vacantes, espolios, etc.). En segundo lugar, estuvo a la cabeza de parte de la colecta del subsidio que el papa solicitó al clero en 1375 para hacer frente a las guerras de Italia. Y, finalmente, estuvo al frente de la percepción de las procuraciones o los derechos de visita. Las procuraciones eran una tasa que debían de pagar los centros eclesiásticos con respecto a la licencia que tenía el obispo pertinente en sus territorios para comprobar el estado de los templos y cultos en sus diócesis. Este derecho quedó fijado durante el pontificado de Benedicto XII en 1336, mediante la bula «Vas electionis", y suponía unos recursos nada desdeñables para las autoridades eclesiásticas. De hecho, ante la compleja situación de la hacienda, los pontífices se reservaron progresivamente durante el siglo XIV estos derechos de visita que debían depositarse en las arcas pontificias. ${ }^{33}$ Veamos a continuación con detenimiento cada una de ellas.

\section{Bernat Vallès y las exacciones pontificias}

Los ingresos que obtuvo Vallès por un sinfín de recaudaciones pontificias ascendieron a 1.442 I. ${ }^{34}$ En particular, 212 I. eran parte de recaudaciones pendientes de provisiones de beneficios o prebendas. ${ }^{35}$ Por ello, tal como se observa en la tabla correspondiente, estos ingresos no alcanzaban grandes sumas porque formaban parte de cantidades que ya habían sido pagadas parcialmente. Uno de los casos que más información nos aporta es el pago de Berenguer de Bigues. En particular, por la provisión y anata del priorato de Santa Anna pagó a Vallès 137 I., si bien el total de la anata ascen-

31 Para el caso de la Corona de Aragón, véanse las síntesis de Bertran Roigé 1990; Morelló Baget 2009; 2013a; 2013c. Para una definición más profunda de cada una de las exacciones: Favier 1966; Lunt 1965.

2 AAV, Coll. 121, ff. 26v-27v; Greiner 1953, 198-199. Durante este periodo, el obispo de Barcelona era Pere de Planella (1371-1385), uno de los grandes mecenas del momento y conocedor de la diócesis (González Reyes 2012, 107-108).

33 Lunt 1965, 406-448; Mollat y Samaran 1905, 34-47 y, en especial, p. 35. Para profundizar en cómo quedaron establecidas las procuraciones durante el pontificado de Benedicto XIII y su relación con la Corona de Aragón, remito a Trenchs i Òdena 1971, II: 88; Bertran Roigé 1997, 287-288.

${ }^{34}$ AAV, Coll. 121, ff. 26r-42r.

35 AAV, Coll. 121, ff. 28r-29v. 
día, por lo menos, a 402 I., cantidad que ya había librado con anterioridad a otro subcolector. Del mismo modo, Ramon de Guixà, prior de Sant Pau del Camp, contribuyó con 25 I. por la provisión del priorato en 1373 , donde se hacía mención a pagas aún pendientes de su antecesor. ${ }^{36}$

Dejando de lado estas cantidades parciales, durante los años en los que Vallès actuó como subcolector percibió unas $1288 \mathrm{I}$. A la hora de hacer una división de los ingresos debemos ser conscientes de que en numerosas ocasiones las vacantes (eso es, aquello que se debía pagar mientras un beneficio estaba desocupado tras el fallecimiento o traslado de su titular) y las anatas (aquello que se pagaba una vez que se designaba un nuevo titular) se contabilizaban como un mismo ingreso. ${ }^{37}$ En particular, las anatas suponían aproximadamente la mitad de los ingresos brutos de un beneficio eclesiástico ordinario durante el primer año de su colación. Y, cuando un beneficio quedaba vacante por fallecimiento o traslado de su titular - especialmente aquellos correspondientes a la alta jerarquía eclesiástica-, parte de las rentas cobradas hasta que se nombraba su sustituto iban destinadas también a las arcas pontificias. ${ }^{38}$ Durante el periodo de Aviñón, los papas confirmaron una y otra vez la reserva de las rentas de los beneficios vacantes y, en algún caso, el propio papado parecía interesado en que estos beneficios quedasen sin designar durante un tiempo para poder percibir sus ingresos. ${ }^{39}$ Por último, el derecho de espolio o ius spolii se cobraba al fallecer un obispo o arzobispo. Los bienes muebles e inmuebles que el mitrado adquiría cuando era promovido a tal dignidad se consideraban que pertenecían a la Iglesia y, por tanto, al morir quedaban excluidos de sus últimas voluntades. En todo este entramado, las cantidades más elevadas que recaudó Vallès (395 I. 6 s.) procedían del espolio y la vacante del monasterio de Santa Eulàlia del Camp tras el fallecimiento del prior Francesc Botella y la designación de Pere Rosell en $1371 .{ }^{40}$ También de la catedral de Barcelona, Vallès pudo percibir unas $455 \mathrm{I}$. de prebendas y preposituras que estaban vacantes en varios altares. Sea como sea, las cantidades medias de estas recaudaciones no eran superiores a las 50 libras (vid. tabla 1).

36 AAV, Coll. 121, f. 28v. Berenguer de Bigues fue prior de Santa Anna entre 1367 y 1384 y un eclesiástico fundamental de la Barcelona del último tercio del trescientos (Jaspert 1996). Ramon de Guixà, fue prior entre 1373 y 1376 (Mutgé i Vives 2008, 88).

37 Favier 1966, 205-208. Contabilizar algunas rentas en un apartado u otro dependía, en ocasiones, del criterio del colector principal y de los datos proporcionados por cada subcolector, quienes estaban al caso de los pormenores de la colecta (Morelló Baget 2009, 77-79).

38 Tal como señalan numerosos autores, la percepción de las anatas también se asocia con los beneficios que quedaban vacantes y, en algunas entradas de la colectoría pontificia, se puede documentar el empleo de ambos términos (vacantes y anatas) de forma simultánea (Favier 1966, 205; Morelló Baget 2009, 77-78).

39 Los intentos de preservar alguna vacante ya han sido puestos de manifiesto en más de una ocasión por los historiadores del papado que han debatido en torno a las ventajas económicas que suponía para la curia esta prolongación de las reservas: Favier 1966, 160-161; Vincke 1932. En particular, Vincke explica cómo, ya en 1316, Juan XXII se reservó los beneficios vacantes de Aragón, además de los de CastiIla, Alemania e Inglaterra y algunos lugares de Francia durante buena parte de su pontificado para disponer de ingresos prolongados en las arcas pontificias.

40 AAV, Coll. 121 , ff. 38 r y $41 v$.

\section{Bernat Vallès y el subsidio de 1375}

En segundo lugar, Vallès fue el encargado de percibir parte de un nuevo subsidio impuesto al clero de Barcelona en 1375. Como hemos indicado, esta ayuda debía servir para nutrir las arcas pontificias, exhaustas también por las guerras de Italia. A grandes rasgos, aunque no conocemos los datos completos, sí que sabemos que Vallès percibió una parte de la recaudación y cantidades pendientes de alguna anualidad anterior. Por ejemplo, todavía como paga del año precedente, el clero de la catedral de Barcelona contribuyó con 275 I. (y que debía complementar a los 500 fl. prometidos). Poco más tarde, el mitrado barcelonés, que debía contribuir con 300 fl., pagó a Vallès 165 I. (quedando pendientes 45 I. para alcanzar los 300 fl. estipulados) (Tabla 2). ${ }^{41}$

Estas sumas fueron depositada en la taula o banco privado de otro conocido cambista local, Guillem Colom, que era encargado de percibir el monto del subsidio..$^{42}$ Uno de los aspectos más sugerentes de este apartado es cómo se produjo la transferencia del dinero a las arcas pontificias desde el banco de Colom hasta los financieros del papa que articulaban la red. A través de un mandato del colector Pere Borrer, Bernat Vallès entregó lo recaudado a una serie de cambistas que, más allá de los límites del principado, operaban con la Cámara Apostólica de Aviñón ${ }^{43}$. En particular, 1.000 fl. de Aragón (550 I.) fueron transferidos a Filippo Soldani, un conocido mercader florentino que se encargó de llevar el dinero a la Cámara Apostólica. ${ }^{44}$ Otros 1.000 fl. (550 I.) fueron entregados a Miguel Pagano y otros 300 fl. (165 I.) a Andrea de Privanca, ambos factores y miembros de la compañía de otro conocido banquero del papa, Andrea Tici. ${ }^{45}$

\section{Bernat Vallès y las procuraciones}

Finalmente, más allá del referido subsidio, Vallès también fue el encargado de percibir las procuraciones o derechos de visitas que debía cobrar el papa en todas las iglesias de la diócesis debido a las dispensas concedidas a los obispos para no llevar a cabo de manera presencial estas visitas. Como hemos dicho, las procuraciones eran los derechos percibidos por los obispos cuando visitaban las iglesias de sus diócesis y que, en varias ocasiones durante el siglo XIV, fueron reservadas al papado. De hecho, si bien en principio las podríamos definir como extraordinarias, desde la década de 1360, con Urbano V (1362-1370), pasaron a ser regulares y permanentes. Durante el pontificado de Gregorio XI (1370-1378) se convirtieron claramente en unos ingresos nada desdeñables para la hacienda pontificia y las reservas de enteras y medias procuraciones afectaban a los territorios de Francia, Provenza, Saboya y Aragón. De hecho, en estos años se iniciaron varias pesquisas sobre los beneficios

41 En este momento (septiembre de 1379), los florines de Cámara equivalían, aproximadamente, a 14 sueldos barceloneses.

42 AAV, Coll. 121, f. 65r-v.

43 Véase para esta cuestión, el estudio clásico de Renouard, quien dedica una parte de su obra a las relaciones financieras entre el papado y la Corona de Aragón (1941, 283, 321 y ss.).

44 AAV, Coll. 121, f. 75r (05/04/1376).

45 AAV, Coll. 121, f. 76v (22/10/1377), f. 78r. Andrea Tici era uno de los banqueros más importantes del papa del momento y operaba por buena parte de la Europa mediterránea trasvasando cantidades monetarias a la hacienda pontificia (Renouard 1941). 
religiosos que habían pagado anteriormente estas rentas para conocer de primera mano su situación económica. ${ }^{46}$

Por esta razón, Bernat Vallès se encargó de recaudar las procuraciones en los deanatos del Vallès y del Penedès, lo que nos permite confirmar de nuevo que conocía bien el terreno y las prácticas administrativas del obispado; ${ }^{47} \sin$ olvidar que estos cobros también servían, por ejemplo, para aclarar otros asuntos relacionados con la recaudación de vacantes y espolios. ${ }^{48}$

Sea como sea, durante el periodo analizado, la mayoría de los complejos religiosos debían abonar 75 sueldos por tal licencia de exoneración en uno o dos plazos, si bien había centros en los que el papa solo se reservaba media procuración ( 37 s. 6 d.) o, en algunos casos, estaban totalmente exentos. ${ }^{49}$ Esto último sucedió con varias iglesias de los deanatos del Barcelonès y del Penedès que, por diversas razones, no contribuyeron a las procuraciones (Santa Maria de Badalona, Sant Pere d'Octavià de Sant Cugat del Vallès, Sant Sebastià de Montbui, Sant Vicenç de Riells, Sant Pau de Riusec, Sant Gervasi, Sant Cristòfol de Begues, Santa Maria de Jàfer, etc.). Muchos de ellos, como Sant Feliu de Vallcarca, se excusaban alegando que no podían hacer frente a tal cantidad por redditus non sufficiunt. ${ }^{50}$ En última instancia, gracias al volumen conservado, sabemos que lo recaudado en los principales centros religiosos por Bernat Vallès ascendieron, según el registro contable, a 595 I. 4 s. ${ }^{51}$ (Tabla 3).

\section{CONSIDERACIONES FINALES}

Bernat Vallès ocupó el cargo de subcolector de la Cámara Apostólica hasta 1378, año en el que el colector general, Pere Borrer, fue procesado y apartado de la gestión pontificia. Esta causa, estudiada ampliamente por L. Grenier, se debió principalmente al intento del colector de seguir cobrando las cantidades que debían ir destinadas a la Cámara Apostólica de Aviñón cuando, desde los primeros años del Cisma, Pedro IV se había apropiado de estas rentas. ${ }^{52}$ En medio de estas circunstancias, Vallès quedó relegado a tareas administrativas y económicas de la Pia Almoina de Barcelona, y siguió ocupando los beneficios eclesiásticos que tenía designados hasta su fallecimiento en $1389 .{ }^{53}$

46 AAV, reg. vat. 263, f. 335 (1371/11/19). Lamentablemente para la Corona de Aragón no hay una tradición historiográfica que se haya ocupado de este asunto de manera general. Para otros territorios del Occidente europeo, véase: Boissellier 2011; Binz 1961. En la Corona de Aragón, este proceso sí ha sido estudiado para el pontificado de Benedicto XIII quien se reservó progresivamente parte de las procuraciones recaudadas en toda la Corona de Aragón durante los primeros años de siglo XV: Morelló Baget 2009, 79-80; Cuella Esteban 2005, 11; Mollat y Samaran 1905, 46-47.

47 La diócesis de Barcelona se dividía en los deanatos del Vallès (que abarcaba también el Pla de Barcelona y el Maresme a partir del rio Besòs, incluida la zona de Sant Celoni) y del Penedès (que se extendía por el Alt y Baix Penedès y el Garraf): Baucells i Reig 1987, 117-118.

48 Favier 1966, 218; Mollat y Samaran 1905, 536.

49 AAV, Coll. 121, f. 44r.

50 AAV, Coll. 121, f. 52v.

51 AAV, Coll. 121, f. 64r.

52 El proceso en cuestión se explica ampliamente en Greiner 1953, 201; Glénisson 1947.

53 Sabemos que Bernat Vallès falleció en 1389 porque sus beneficios quedaron vacantes y fueron designados ese mismo año al canónigo de Barcelona Francesc Alanya (Batlle i Gallart 1988, 317).
A lo largo de estas páginas hemos puesto de relieve el papel que jugó uno de los llamados primeros diputados o diputados a la cabeza de la Generalitat en relación con las finanzas regia, eclesiástica y pontificia durante el último tercio del siglo XIV. En primer lugar, se ha visto que su función como diputado de la incipiente Diputación del General consistía en ser partícipe activo de la colecta del donativo otorgado en las Cortes de 1365 a través de los mecanismos de recaudación ya mencionados. Si bien su posición como eclesiástico le hacía tener un papel predominante respecto a los otros diputados, debemos remarcar de nuevo que la labor de los diputados durante estas décadas fue puramente técnica y temporal, y hasta el siglo XV no se definió un aura política más destacada en torno a estos.

En segundo lugar, hemos mostrado cómo durante los mismos años en los que Bernat Vallès actuó al frente de la recaudación del donativo, también fue subcolector eclesiástico en el obispado de Barcelona de la décima pontificia promulgada en 1365 por el papa Urbano V. Asimismo, las noticias sobre su labor como recaudador de las tallas del concilio de Tarragona de 1369, su presencia en las Cortes de Tarragona, Montblanc y Tortosa de 1370 y su actividad como administrador de la Pía Almoina de Barcelona nos ayudan a comprender el interesante cursus honorum seguido por nuestro protagonista, que, hasta el momento, había pasado casi desapercibido. Y es que, como decíamos, su trayectoria anterior y su labor como subcolector de la Cámara Apostólica a mediados de la década de 1370 reafirma la idea ya mencionada de que era buen conocedor del terreno y de las finanzas pontificias y regias. Para constatar esta afirmación tan solo hace falta observar el amplio listado de las iglesias de la diócesis de Barcelona por las que actuó Vallès y el exhaustivo control que ejerció sobre las procuraciones y otras exacciones pontificias como las vacantes.

En tercer lugar, hemos documentado lo que recaudó Vallès a lo largo de todo el periodo. De la décima bienal de 1365 , Vallès presentó unas cuentas que ascendían a 68.733 s. (3.436 I. aprox.); de los ingresos heterogéneos de las exacciones pontificias de 1375 (fundamentalmente vacantes y anatas), 1.442 I.; de parte del subsidio pontificio de ese mismo año, 473 I.; y, finalmente, de las procuraciones anuales de 1375 , Bernat Vallès percibió 595 I. Tal como hemos indicado, estas cantidades tenían como destino las arcas de las haciendas regia y pontificia, y, por ello, hemos podido reconstruir, aunque sea de modo indirecto, la relación financiera que tuvo Vallès con los principales banqueros del momento, tanto con aquellos que actuaban como prestamistas de la monarquía la Corona de Aragón (y que, por ello tenían asignadas varias rentas) como aquellos que desempeñaban su actividad financiera con el papado. En este sentido, hemos podido seguir el trazo de los principales gestores y beneficiarios del donativo de las Cortes de 1365 y de los ingresos de la décima bienal. Por otro lado, también hemos podido comprobar cómo parte de las recaudaciones de las exacciones pontificias percibidas por Vallès iban a parar a compañías de banqueros como la de Andrea Tici a través de una interesante $-\mathrm{y}$ aún poco conocida - trama financiera donde participaban un gran número de cambistas locales e internacionales. 
En conclusión, todo parece indicar que la gestión de Bernat Vallès como diputado en el donativo de las Cortes de Tortosa, unida a su actividad en relación con la décima, le favoreció a la hora de ser nombrado subcolector apostólico una década más tarde. Sin embargo, dado que a día de hoy seguimos sin conocer el papel que pudieron desempeñar otros diputados eclesiásticos en las haciendas regia y pontificia, no podemos establecer muchos paralelismos. Pese a que hemos señalado otros perfiles biográficos del género, como los de Berenguer de Cruïlles o Romeu Sescomes para el siglo XIV, o el de Domingo Ram para un periodo posterior, tan solo un estudio más profundo nos ayudará a conocer mejor estas figuras tan polifacéticas. Todo ello, sin duda, será muy necesario para entender el papel real que tuvieron los eclesiásticos en la implantación de la reciente Diputación del General de Cataluña durante las primeras décadas, así como su labor en la curia pontificia durante un periodo tan trascendental como el del papado de Aviñón y el Cisma de Occidente.

\section{ANEXos}

\section{TABLA 1}

\section{Conjunto de exacciones pontificias recaudadas por Bernat Vallès}

\section{Restas pendientes de percibir}

\begin{tabular}{|l|c|}
\hline Provisión de beneficio. Guillem Sagrera. Altar de Sant Miquel de la catedral de Barcelona & $8 \mathrm{I}$. \\
\hline Provisión de beneficio. Ramon de Guixà. Priorato de Sant Pau del Camp & $25 \mathrm{I} .17 \mathrm{~s}$. \\
\hline Provisión de beneficio. Berenguer de Bigues. Priorato de Santa Anna & $33 \mathrm{I}$. \\
\hline Prebenda. Francesc Ermengol. Priorato de Santa Anna & $10 \mathrm{I}$. \\
\hline Provisión de beneficio. Bartomeu Morgades. Parroquia de Sant Vicenç de Morrocurt & $10 \mathrm{I}$. \\
\hline Anata y prebenda. Guillem de Cornac. Parroquia de Sant Vicenç de Morrocurt & $22 \mathrm{I}$. \\
\hline Anata. Berenguer de Bigues. Priorato de Santa Anna & $104 \mathrm{I}$. \\
\hline Total & $212 \mathrm{I} .17 \mathrm{~s}$. \\
\hline
\end{tabular}

\section{Anatas, vacantes y prebendas}

\begin{tabular}{|c|c|}
\hline Vacante. Canonicato y prebenda de la catedral de Barcelona & 271. \\
\hline Vacante. Prebenda de la catedral & 271. \\
\hline Vacante. Prebenda de la catedral & 271. \\
\hline Vacante. Prebenda de la catedral & $31 \mathrm{l}$. \\
\hline Vacante. Prebenda de la catedral & $27 \mathrm{I}$. \\
\hline Vacante. Prebenda de la catedral & $27 \mathrm{I}$. \\
\hline Prepositura de abril & 701. \\
\hline Vacante. Capellanías de la catedral & $36 \mathrm{I}$. \\
\hline Prepositura de diciembre & $36 \mathrm{l}$. \\
\hline Vacante. Prebenda de la catedral & $53 \mathrm{I}$. \\
\hline Vacante. Prebenda de la catedral & $27 \mathrm{I}$. \\
\hline Vacante. Diácono de la catedral & $15 \mathrm{l}$. \\
\hline Vacante. Beneficio en el altar de Santa Anna de la catedral & $13 \mathrm{I}$. \\
\hline Vacante. Presbitero en el altar de Santa Eulàlia de la catedral & $20 \mathrm{I}$. \\
\hline Vacante. Beneficio en el altar de Sant Joan de la catedral & $8 I$. \\
\hline Vacante. Beneficio en el altar de Sant Bartolomeu de la catedral & $13 \mathrm{l} .15 \mathrm{~s}$. \\
\hline Vacante. Vicaría de Santa Maria del Mar & $55 \mathrm{l}$. \\
\hline Vacante. Iglesia de Santa Perpètua de Mogoda & $41 \mathrm{l} .10 \mathrm{~s}$. \\
\hline Vacante. Iglesia de Sant Andreu de Barcelona & $40 \mathrm{l}$. \\
\hline Vacante. Iglesia de Sant Vicenç de Castellbisbal & $18 \mathrm{I}$. \\
\hline Vacante. Iglesia de Sant Jaume de Barcelona & $35 \mathrm{I}$. \\
\hline Vacante. Iglesia de Santa Engràcia de Montcada & - \\
\hline Vacante. Ebdomadario menor de Sant Pere de Vilamajor & $30 \mathrm{l}$. \\
\hline Vacante. Rector de Santa Magdalena de Bonastre & $17 \mathrm{l} .10 \mathrm{~s}$. \\
\hline Vacante. Rector de Sant Genís dels Agudells & $38 \mathrm{l} .10 \mathrm{~s}$. \\
\hline Vacante. Frutos de Santa Maria de Mediona & $42 \mathrm{l} .10 \mathrm{~s}$. \\
\hline Vacante. Beneficio en el altar de Sant Martí de la catedral & $6 \mathrm{I} .12 \mathrm{~s}$. \\
\hline Anata. Varias (pagadas por Berenguer de Bellsolà) & $55 \mathrm{I}$. \\
\hline Anata. Varias (pagadas por Berenguer de Bellsolà) & $27 \mathrm{l}$. \\
\hline Anata. Beneficio en el altar de Sant Lluc de la catedral & $12 \mathrm{l} .6 \mathrm{~s}$. \\
\hline Anata. Rector de Sant Cristòfol de la Granada & $20 \mathrm{l}$. \\
\hline Anatas. Iglesia de Sant Joan Despí & $30 \mathrm{l}$. \\
\hline Vacante. Priorato del monasterio de Santa Eulàlia del Camp & $275 \mathrm{I}$. \\
\hline Espolio. Priorato del monasterio de Santa Eulàlia del Camp & $110 \mathrm{I}$. \\
\hline Anata. Rector de Sant Iscle y Sant Fèlix & $11 \mathrm{l}$. \\
\hline Total aprox. & 1.442 I. 9 s. $4 d^{54}$ \\
\hline
\end{tabular}

54 AAV, Coll. 121, f. 42r. La suma real de la tabla asciende a 1.319 libras, ya que no hemos incluido pequeñas cantidades que corresponden a arriendos de prebendas y preposituras y que nos ha resultado complicado sistematizar en la tabla (AAV, Coll. 121, ff. 32v-35r). 
TABLA 2

Recaudación de Bernat Vallès del subsidio pontificio de 1375

\begin{tabular}{|l|c|}
\hline Clero de la catedral de Barcelona y resto de la diócesis 55 & $275 \mathrm{I}$. \\
\hline Abad de Sant Cugat (por composición) & $33 \mathrm{I}$. \\
\hline Obispo de Barcelona (de 300 fl. solicitados) & $165 \mathrm{I}$. \\
\hline Total & $473 \mathrm{I}$. \\
\hline
\end{tabular}

\section{TABLA 3}

\section{ReCaudación de B. Vallès del pago de las PROcuraciones de los deanatos del Vallès y del Penedès ${ }^{56}$}

\section{Deanato del Vallès}

\begin{tabular}{|c|c|c|}
\hline Catedral de Barcelona & $125 \mathrm{~s}$. & Dos plazos \\
\hline Santa Maria del Mar (Barcelona) & $75 \mathrm{~s}$. & Dos plazos \\
\hline Santa Maria del Pi (Barcelona) & $75 \mathrm{~s}$. & Dos plazos \\
\hline Sant Just (Barcelona) & $75 \mathrm{~s}$. & Dos plazos \\
\hline Sant Jaume (Barcelona) & $75 \mathrm{~s}$. & Dos plazos \\
\hline Sant Miquel (Barcelona) & $75 \mathrm{~s}$. & Dos plazos \\
\hline Sant Cugat del Rec (Barcelona) & $75 \mathrm{~s}$. & Dos plazos \\
\hline Sant Pere de les Puel-les (Barcelona) & $100 \mathrm{~s}$. & Dos plazos \\
\hline Santa Eulàlia del Camp (Barcelona) & $75 \mathrm{~s}$. & Dos plazos \\
\hline Abadía de Sant Cugat del Vallès & $100 \mathrm{~s}$. & Dos plazos \\
\hline Sant Pau del Camp & $100 \mathrm{~s}$. & Dos plazos \\
\hline Abadía de Sant Llorenç del Munt & $75 \mathrm{~s}$. & Dos plazos \\
\hline Monasterio de Sant Miquel del Fai & $75 \mathrm{~s}$. & Dos plazos \\
\hline Priorato de Sabadell & $75 \mathrm{~s}$. & Un plazo \\
\hline Monasterio de Sant Genís de Rocafort & $75 \mathrm{~s}$. & Dos plazos \\
\hline Monasterio de Santa Oliva de l'Arboç & $75 \mathrm{~s}$. & Un plazo \\
\hline Monasterio de Sant Ponç de Corbera & 37 s. 6 d. & Dos plazos \\
\hline Monasterio de Sant Pere de Riudebitlles & $75 \mathrm{~s}$. & Dos plazos \\
\hline Monasterio de Sant Sebastià dels Gorgs & $75 \mathrm{~s}$. & Dos plazos \\
\hline Sant Quintí de Mediona & $75 \mathrm{~s}$. & Dos plazos \\
\hline Prior de Terrassa & $75 \mathrm{~s}$. & Un plazo \\
\hline Sant Martí de Riells & $75 \mathrm{~s}$. & Un plazo \\
\hline Sant Esteve de Bruguera & $75 \mathrm{~s}$. & Dos plazos \\
\hline Sant Vicenç de Gualba & $75 \mathrm{~s}$. & Dos plazos \\
\hline Sant Joan de Campins & $75 \mathrm{~s}$. & Un plazo \\
\hline Sant Martí de Mosqueroles & $75 \mathrm{~s}$. & Dos plazos \\
\hline Sant Esteve de Costa & $75 \mathrm{~s}$. & Dos plazos \\
\hline Sant Cristòfol de Falgars & $75 \mathrm{~s}$. & Un plazo \\
\hline Sant Julià del Montseny & $75 \mathrm{~s}$. & Dos plazos \\
\hline Sant Esteve de Palautordera & $45 \mathrm{~s}$. & Un plazo \\
\hline Sant Esteve de Palautordera & $30 \mathrm{~s}$. & Dos plazos \\
\hline Santa Maria de Palautordera & $75 \mathrm{~s}$. & Dos plazos \\
\hline Sant Martí de Pertegàs & $75 \mathrm{~s}$. & Un plazo \\
\hline Sant Martí de Montnegre & $75 \mathrm{~s}$. & Dos plazos \\
\hline Sant Llorenç de Vilardell & $75 \mathrm{~s}$. & Dos plazos \\
\hline Sant Esteve d'Olzinelles & $75 \mathrm{~s}$. & Dos plazos \\
\hline Sant Andreu de Vallgorguina & $75 \mathrm{~s}$. & Dos plazos \\
\hline Sant Pere de Vilamajor y Santa Susanna & $75 \mathrm{~s}$. & Dos plazos \\
\hline Sant Julià del Fou & $75 \mathrm{~s}$. & Dos plazos \\
\hline Sant Julià de Santa Basilissa & $25 \mathrm{~s}$. & Dos plazos \\
\hline Santa Maria de Serra & $16 \mathrm{~s} .8 \mathrm{~d}$. & Dos plazos \\
\hline Sant Sadurní de Collsabadell & 33 s. 4 d. & Un plazo \\
\hline Santa Maria de Llinars y Sant Andreu & $75 \mathrm{~s}$. & Dos plazos \\
\hline Santa Maria de Cardedeu y Sant Esteve de Coll & $75 \mathrm{~s}$. & Dos plazos \\
\hline Santa Agnès de Malanyanes & $75 \mathrm{~s}$. & Dos plazos \\
\hline Sant Sadurní de Roca & $75 \mathrm{~s}$. & Dos plazos \\
\hline Sant Esteve de Vilanova & $75 \mathrm{~s}$. & Dos plazos \\
\hline
\end{tabular}

55 Esta cantidad forma parte del subsidio de 500 fl. que ya había solicitado anteriormente el papa a la Iglesia de Barcelona.

56 Conviene recordar de nuevo que la diócesis de Barcelona se dividía en los deanatos del Vallès (que abarcaba también el Pla de Barcelona y el Maresme a partir del rio Besos, incluida la zona de Sant Celoni) y del Penedès (que se extendía por el Alt y Baix Penedès y el Garraf): Baucells i Reig 2004, 117-118. 


\begin{tabular}{|c|c|c|}
\hline Santa Maria de Montmeló & 37 s. 6 d. & Un plazo \\
\hline Sant Vicenç de Vallromanes & 37 s. 6 d. & Dos plazos \\
\hline Santa Maria de Martorelles & $25 \mathrm{~s}$. & Dos plazos \\
\hline Sant Cebrià de Cabanyes & $25 \mathrm{~s}$. & Dos plazos \\
\hline Sant Fost de Campsentelles & $25 \mathrm{~s}$. & Dos plazos \\
\hline Sant Pere de Reixac & $75 \mathrm{~s}$. & Dos plazos \\
\hline Sant Martí de Provençal & $75 \mathrm{~s}$. & Dos plazos \\
\hline Sant Adrià de Besòs & $25 \mathrm{~s}$. & Dos plazos \\
\hline Santa Engràcia de Besòs & $25 \mathrm{~s}$. & Dos plazos \\
\hline Santa Coloma de Gramenet & $75 \mathrm{~s}$. & Dos plazos \\
\hline Santa Maria de Badalona & -57 & - \\
\hline Sant Cebrià de Tiana & $75 \mathrm{~s}$. & Dos plazos \\
\hline Sant Feliu d'Alella & $75 \mathrm{~s}$. & Dos plazos \\
\hline Sant Martí de Teià & $75 \mathrm{~s}$. & Dos plazos \\
\hline Sant Pere de Premià & $75 \mathrm{~s}$. & Dos plazos \\
\hline Sant Genís de Vilassar & $75 \mathrm{~s}$. & Dos plazos \\
\hline Sant Feliu de Cabrera & $75 \mathrm{~s}$. & Dos plazos \\
\hline Sant Julià d'Argentona & $75 \mathrm{~s}$. & Dos plazos \\
\hline Santa Maria de Mataró y Sant Martí de Mata & $75 \mathrm{~s}$. & Dos plazos \\
\hline Sant Andreu de Llavaneres & $75 \mathrm{~s}$. & Dos plazos \\
\hline Sant Iscle y Santa Victòria de Dosrius & $75 \mathrm{~s}$. & Un plazo \\
\hline Sant Muç de Cànoves & $75 \mathrm{~s}$. & Dos plazos \\
\hline Santa Coloma de Marata & $75 \mathrm{~s}$. & Dos plazos \\
\hline Sant Mamet de Corró d’Amunt & $75 \mathrm{~s}$. & Dos plazos \\
\hline Santa Eulàlia de Corró d’Avall & $75 \mathrm{~s}$. & Dos plazos \\
\hline Sant Andreu de Samalús & $75 \mathrm{~s}$. & Dos plazos \\
\hline Santa Maria de Llerona & $75 \mathrm{~s}$. & Dos plazos \\
\hline Sant Pau de Montmany & 18 s. 9 d. & Dos plazos \\
\hline Sant Esteve de La Garriga & 37 s. 6 d. & Dos plazos \\
\hline Sant Cristòfol de Monteugues & 18 s. 9 d. & Dos plazos \\
\hline Sant Feliu de Canovelles & $75 \mathrm{~s}$. & Un plazo \\
\hline Sant Esteve de Granollers & $75 \mathrm{~s}$. & Dos plazos \\
\hline Sant Julià de Palou & $75 \mathrm{~s}$. & Dos plazos \\
\hline Sant Julià de Lliçà d'Amunt & $75 \mathrm{~s}$. & Dos plazos \\
\hline Sant Cristòfol de Lliçà d’Avall & $75 \mathrm{~s}$. & Dos plazos \\
\hline Sant Esteve de Parets & $75 \mathrm{~s}$. & Dos plazos \\
\hline Sant Vicenç de Mollet & $75 \mathrm{~s}$. & Dos plazos \\
\hline Sant Esteve de Ripollet & $75 \mathrm{~s}$. & Dos plazos \\
\hline Santa Maria de Barberà & $75 \mathrm{~s}$. & Dos plazos \\
\hline Santa Maria de Santiga & $75 \mathrm{~s}$. & Dos plazos \\
\hline Sant Salvador de Polinyà & $75 \mathrm{~s}$. & Dos plazos \\
\hline Santa Perpètua de Mogoda & $75 \mathrm{~s}$. & Dos plazos \\
\hline Santa Maria de Palau-solità & $75 \mathrm{~s}$. & Dos plazos \\
\hline Sentmenat & $75 \mathrm{~s}$. & Dos plazos \\
\hline Santa Maria de Caldes de Montbui & $75 \mathrm{~s}$. & Dos plazos \\
\hline Sant Esteve de Palaudàries & $25 \mathrm{~s}$. & Dos plazos \\
\hline Santa Maria de Gallecs & $25 \mathrm{~s}$. & Dos plazos \\
\hline Sant Genís de Plegamans & $25 \mathrm{~s}$. & Dos plazos \\
\hline Sant Genís d’Ametlla & $75 \mathrm{~s}$. & Un plazo \\
\hline Santa Eulàlia de Ronçana & $75 \mathrm{~s}$. & Dos plazos \\
\hline Sant Pere de Bigues & $75 \mathrm{~s}$. & Dos plazos \\
\hline Sant Feliu de Codines & $75 \mathrm{~s}$. & Dos plazos \\
\hline Sant Feliu de Gallifà & $75 \mathrm{~s}$. & Dos plazos \\
\hline Sant Feliu de Vallcarca & 12 s. 6 d. ${ }^{58}$ & Un pago \\
\hline Sant Feliu de Castellar & $25 \mathrm{~s}$. & Dos plazos \\
\hline Sant Joan de Matadepera & $25 \mathrm{~s}$. & Dos plazos \\
\hline Santa Maria d'Ullastrell & 12 s. $6 \mathrm{~d}$. & Un plazo \\
\hline Sant Esteve de Castellet & $75 \mathrm{~s}$. & Dos plazos \\
\hline Sant Vicenç de Jonqueres & $75 \mathrm{~s}$. & Un plazo \\
\hline Sant Julià d'Altura & $75 \mathrm{~s}$. & Dos plazos \\
\hline Sant Feliu d'Arraona & $75 \mathrm{~s}$. & Dos plazos \\
\hline Sant Quirze de Galliners & 37 s. 6 d. & Dos plazos \\
\hline Santa Maria d'Olesa de Montserrat & $75 \mathrm{~s}$. & Dos plazos \\
\hline
\end{tabular}

57 Estaba tasada en 75 s., pero no se llegaron a hacer efectivos los pagos: AAV, Coll, reg. 121, f. 49r.

57 Debía contribuir con 75 s., pero no alcanza a pagar la suma total. 
Sant Vicenç de Castellbisbal

Santa Eulàlia de Papiol

Santa Creu d'Olorda

Sant Miquel de Molins de Rei

Sant Pere de Rubí

Santa Maria de Vallvidrera

Santa Maria de Campanyà

Sant Feliu de Vilamilans

Sant Pere d'Octavià de Sant Cugat del Vallès

Sant Cebrià de Valldoreix

Sant Martí de Cerdanyola

Sant Sant Iscle de les Feixes

Sant Genís dels Agudells y Sant Joan d'Horta

Sant Andreu de Palomar

Sant Vicenç de Sarrià

Sant Just Desvern

Santa Maria Magdalena d'Esplugues

Sant Joan Despí

Santa Maria de Cornellà

Santa Eulàlia Provençana

Sant Sebastià de Montbui

Sant Vicenç de Riells

Sant Pau de Riusec

Sant Gervasi

Sant Pere de Clarà

\begin{tabular}{|c|c|}
\hline $75 \mathrm{~s}$. & Dos plazos \\
\hline $75 \mathrm{~s}$. & Dos plazos \\
\hline $60 \mathrm{~s}$. & Un plazo \\
\hline $15 \mathrm{~s}$. & Dos plazos \\
\hline $75 \mathrm{~s}$. & Dos plazos \\
\hline $25 \mathrm{~s}$. & Dos plazos \\
\hline $25 \mathrm{~s}$. & Dos plazos \\
\hline $25 \mathrm{~s}$. & Dos plazos \\
\hline- & - \\
\hline $75 \mathrm{~s}$. & Dos plazos \\
\hline $75 \mathrm{~s}$. & Dos plazos \\
\hline $75 \mathrm{~s}$. & Dos plazos \\
\hline $75 \mathrm{~s}$. & Un plazo \\
\hline $75 \mathrm{~s}$. & Dos plazos \\
\hline $75 \mathrm{~s}$. & Dos plazos \\
\hline $75 \mathrm{~s}$. & Dos plazos \\
\hline $37 \mathrm{~s} .6 \mathrm{~d}$. & Dos plazos \\
\hline $75 \mathrm{~s}$. & Dos plazos \\
\hline $75 \mathrm{~s}$. & Dos plazos \\
\hline $75 \mathrm{~s}$. & Un plazo \\
\hline- & - \\
\hline- & - \\
\hline- & - \\
\hline $75 \mathrm{~s}$. & - \\
\hline & Dos plazos \\
\hline
\end{tabular}

\section{Deanato del Penedès}

\begin{tabular}{|c|c|c|}
\hline Sant Boi & $75 \mathrm{~s}$. & Dos plazos \\
\hline Sant Climent & $75 \mathrm{~s}$. & Dos plazos \\
\hline Sant Pere de Gavà & $75 \mathrm{~s}$. & Dos plazos \\
\hline Santa Maria de Castelldefels & 37 s. $6 \mathrm{~d}$. & Dos plazos \\
\hline Sant Cristòfol de Begues & - & - \\
\hline Sant Pere d'Olivella & 12 s. $6 \mathrm{~d}$. & Un plazo \\
\hline priorato de Garraf & $25 \mathrm{~s}$. & Dos plazos \\
\hline Santa Maria de Jàfer & - & - \\
\hline Santa Tecla de Sitges & $75 \mathrm{~s}$. & Dos plazos \\
\hline Sant Pere de Ribes & $75 \mathrm{~s}$. & Un plazo \\
\hline Santa Maria de La Geltrú & $75 \mathrm{~s}$. & Un plazo \\
\hline Santa Maria de Cubelles & $75 \mathrm{~s}$. & Dos plazos \\
\hline Sant Cristòfol de Cunit & 37 s. $6 \mathrm{~d}$. & Dos plazos \\
\hline Santa Creu de Calafell & 37 s. $6 \mathrm{~d}$. & Dos plazos \\
\hline Sant Vicenç de Calders & 37 s. 6 d. & Dos plazos \\
\hline Sant Salvador de Vendrell & 37 s. 6 d. & Dos plazos \\
\hline Sant Pere de Gornal & $45 \mathrm{~s}$. & Dos plazos \\
\hline Santa Maria de Bellvei & $30 \mathrm{~s}$. & Dos plazos \\
\hline Sant Bartomeu d'Albinyana & 37 s. 6 d. & Dos plazos \\
\hline Santa Maria Magdalena de Bonastre & 37 s. 6 d. & Dos plazos \\
\hline Santa Maria de Salomó & 37 s. 6 d. & Dos plazos \\
\hline Santa Maria de Puigtinyós & $75 \mathrm{~s}$. & Dos plazos \\
\hline Santa Maria de Vilarodona & $75 \mathrm{~s}$. & Dos plazos \\
\hline Sant Miquel de Montmell & 37 s. 6 d. & Dos plazos \\
\hline Santa Maria d'Albà & 37 s. 6 d. & Dos plazos \\
\hline Sant Cristòfol de Selma & 37 s. 6 d. & Dos plazos \\
\hline Sant Miquel de Marmellar & 37 s. 6 d. & Dos plazos \\
\hline Sant Joan de Pontons & $75 \mathrm{~s}$. & Dos plazos \\
\hline Sant Pere de Vilademàger & $75 \mathrm{~s}$. & Dos plazos \\
\hline Santa Maria de Miralles & $75 \mathrm{~s}$. & Dos plazos \\
\hline Santa Maria de Mediona & $75 \mathrm{~s}$. & Dos plazos \\
\hline Sant Pere de Claramunt & $75 \mathrm{~s}$. & Dos plazos \\
\hline Santa Maria de Foix & $75 \mathrm{~s}$. & Dos plazos \\
\hline Sant Salvador de Cabrera & - & - \\
\hline Sant Miquel d’Orpí & 37 s. 6 d. & Dos plazos \\
\hline Santa Maria de Capellades & 37 s. $6 \mathrm{~d}$ & Dos plazos \\
\hline Sant Pau de la Guàrdia y Santa Maria del Bruc & $75 \mathrm{~s}$. & Dos plazos \\
\hline Sant Pere de Pierola & - & - \\
\hline Sant Corneli de Collbató & 37 s. $6 \mathrm{~d}$. & Dos plazos \\
\hline Sant Esteve Sesrovires & $75 \mathrm{~s}$. & Dos plazos \\
\hline
\end{tabular}




\begin{tabular}{|c|c|c|}
\hline Sant Pere d'Abrera & $75 \mathrm{~s}$. & Dos plazos \\
\hline Santa Maria d'Esparreguera & $75 \mathrm{~s}$. & Dos plazos \\
\hline Sant Pere de Masquefa & 37 s. 6 d. & Dos plazos \\
\hline Santa Maria de Piera y Sant Jaume Sesoliveres & $75 \mathrm{~s}$. & Dos plazos \\
\hline Sant Pere de Gelida, Sant Joan Samora y Sant Llorenç d'Hortons & $75 \mathrm{~s}$. & Dos plazos \\
\hline Sant Pere de Subirats & 37 s. 6 d. & Dos plazos \\
\hline Sant Sadurní de Subirats & 37 s. 6 d. & Dos plazos \\
\hline Santa Maria de Monistrol d'Anoia & 37 s. $6 \mathrm{~d}$. & Un plazo \\
\hline Sant Pere de Lavern & 37 s. 6 d. & Dos plazos \\
\hline Santa Maria de Santa Fe & 37 s. 6 d. & Dos plazos \\
\hline Sant Pere d’Avinyó & $75 \mathrm{~s}$. & Dos plazos \\
\hline Sant Cristòfol de la Granada & $75 \mathrm{~s}$. & Dos plazos \\
\hline Santa Maria de la Torre de Ferran & 37 s. 6 d. & Dos plazos \\
\hline Sant Pere de Molanta & 37 s. 6 d. & Dos plazos \\
\hline Sant Salvador de Sesgunyoles (Les Gunyoles) & 37 s. 6 d. & Dos plazos \\
\hline Sant Cugat Sesgarrigues & 37 s. 6 d. & Dos plazos \\
\hline Santa Maria de Vilafranca & $75 \mathrm{~s}$. & Dos plazos \\
\hline Sant Miquel d'Olèrdola & $75 \mathrm{~s}$. & Dos plazos \\
\hline Santa Maria de Moja & 18 s. 9 d. & Un plazo \\
\hline Santa Margarida d'Olèrdola & 37 s. 6 d.. & Dos plazos \\
\hline Sant Pere de Castellet & $75 \mathrm{~s}$. & Dos plazos \\
\hline Sant Esteve de Masdovelles & - & - \\
\hline Sant Julià de l'Arboç & $75 \mathrm{~s}$. & Dos plazos \\
\hline Santa Eulàlia de Banyeres & $75 \mathrm{~s}$. & Dos plazos \\
\hline Santa Margarida de La Bisbal & $75 \mathrm{~s}$. & Un plazo \\
\hline Sant Jaume dels Domenys & $75 \mathrm{~s}$. & Dos plazos \\
\hline Sant Sadurní de Castellví & $75 \mathrm{~s}$. & Dos plazos \\
\hline Sant Marçal de Castellet & $20 \mathrm{~s}$. & Un plazo \\
\hline Sant Ponç de Papiol & - & - \\
\hline Prepósito de Papiol & $75 \mathrm{~s}$. & Un plazo \\
\hline Santa Maria de Bleda & $50 \mathrm{~s}$. & Dos plazos \\
\hline Sant Genís de Pacs & $25 \mathrm{~s}$. & Dos plazos \\
\hline Sant Llorenç & $8 \mathrm{~s}$. & Dos plazos \\
\hline Santa Maria de Corbera & $75 \mathrm{~s}$. & Dos plazos \\
\hline Santa Maria de Castellví de Rosanes & $75 \mathrm{~s}$. & Dos plazos \\
\hline Sant Andreu de la Barca & $25 \mathrm{~s}$. & Dos plazos \\
\hline Santa Maria de Martorell & $75 \mathrm{~s}$. & Dos plazos \\
\hline Sant Vicenç dels Horts & - & - \\
\hline Sant Esteve de Cervelló & $75 \mathrm{~s}$. & Dos plazos \\
\hline Santa Coloma de Cervelló & $50 \mathrm{~s}$. & Dos plazos \\
\hline Sant Martí de Torrelles & $25 \mathrm{~s}$. & Dos plazos \\
\hline Sant Martí de Foix & $75 \mathrm{~s}$. & Un plazo \\
\hline Sant Pere de Font-rubí & 37 s. 6 d. & Dos plazos \\
\hline Sant Vicenç de Morrocurt & 37 s. 6 d. & Dos plazos \\
\hline Sant Marçal de Terrassola & $75 \mathrm{~s}$. & Un plazo \\
\hline Santa Maria de Lavit & $75 \mathrm{~s}$. & Dos plazos \\
\hline Sant Valentí de Vilafranca & - & - \\
\hline Santa Maria de Vallformosa & 12 s. 6 d. & Un plazo ${ }^{59}$ \\
\hline Sant Salvador de Durban & - & - \\
\hline Sant Esteve de Castellet & 12 s. $6 \mathrm{~d}$ & Un plazo \\
\hline Sant Joan d'Olesa de Bonesvalls & $10 \mathrm{~s}$. & Dos plazos \\
\hline Sant Pau d'Ordal & -60 & - \\
\hline Santa Maria de Banyeres & $40 \mathrm{~s}$. & Un plazo \\
\hline
\end{tabular}




\section{BIBLIOGRAFÍA FINAL}

Abril i López. Josep M. 1995. «Un retaule de Destorrents i el canonge celoní Bernat Vallès». Monografies del Montseny 10, 85-97.

Batlle i Gallart, Carme. 1988. "La ciutat de Barcelona i el Cisma». En Jornades sobre el Cisma d'Occident a Catalunya, les Illes i el País Valencià (Barcelona-Peníscola 1979), vol. 2, 315-325. Barcelona: Institut d'Estudis Catalans.

Baucells i Reig. Josep. 1973. "La Pia Almoina de la Seo de Barcelona: origen y desarrollo». En A pobreza e a assistência aos pobres na Península Ibérica durante a Idade Média: 73-135. Lisboa: Instituto de Alta Cultura - Centro de Estudos Históricos.

Baucells i Reig. Josep. 1987. El Maresme i la Pia Almoina de la Seu de Barcelona: catàleg del fons en pergamí de l'Arxiu Capitular de la Catedral de Barcelona. Barcelona: Generalitat de Catalunya.

Baucells i Reig. Josep. 2004. Vivir en la Edad Media: Barcelona y su entorno en los siglos XIII y XIV (1200-1344). 2 vols, Barcelona: CSIC.

Bertran Roigé, Prim. 1990. «El poder de l'Església medieval: organització administrativa i sistema fiscal en el segle XIV». L'Avenç 139: 66-69.

Bertran Roigé, Prim. 1997. «La fiscalitat eclesiàstica en els bisbats catalans (1384-1392). Tipologies impositives y diferències territorials». Acta historica et archaeologica Mediaevalia 18: 281-300.

Binz, Louis. 1961. "Á propos d’une levée de procurations dans le diocèse de Genève en 1361». Mélanges offerts à M. Paul-E. Martin. MDG 40: 387-400.

Boissellier, Stéphane. 2011. «Décimes et réserves des procurations dans la collectorie portugaise (1279-1 1371). L'aport des registres fiscaux pontificaux». En El dinero de Dios. Iglesia y fiscalidad en el Occidente Medieval (siglos XIII-XV), ed. Denis Menjot y Manuel Sánchez, 71-87. Madrid: Instituto de Estudios Fiscales.

Carocci, Sandro y Amadeo De Vicentis. 2017. La mobilità sociale nel Medioevo italiano. 3. II mondo ecclesiastico. Roma: Viella.

Cortes de Cataluña. 1899. Cortes de los Antiguos Reinos de Aragón y de Valencia y Principado de Cataluña. Tomo II. Comprende desde el año 1359 al 1367. 1899. Madrid: Real Academia de la Historia.

Cuella Esteban, Ovidio. 2005. Bulario Aragonés de Benedicto XIII. Vol. II. La Curia itinerante (1404-1411). Zaragoza: Institución Fernando el Católico.

De Puig i Oliver, Jaume y Josep Marquès Planagumà. 2007. «Els darrers documents del primer president de la Generalitat, Berenguer de Cruilles, bisbe de Girona (1359-1362)». Arxiu de textos catalans antics 26: 283-284.

De Puig i Oliver, Jaume y Josep Marquès Planagumà. 2008. «Els darrers documents del primer president de la Generalitat, Berenguer de Cruilles, bisbe de Girona (1359-1362)». Arxiu de textos catalans antics 27: 7-43.

Eubel, Conrad. 1913. Hierarchia catholica medii aevi, sive Summorum pontificum, S.R.E. cardinalium, ecclesiarum antistitum series ab anno 1198 usque ad annum 1605. Vol. 1 (1198-1431). Münster: Sumptibus et typis Librariae Regensbergianae.

Favier, Jean. 1966. Les finances pontificales à l'époque du Ggrand sSchisme d'Occident (1378-1409). Paris: École Française d'Athenes et de Rome.

Ferrer i Mallol, M. $\underline{a}$ Teresa. 1984. «Els primers diputats de la Generalitat de Catalunya (1359-1412)». En Miquel Coll i Alentorn. Miscel·lània d'homenatge en el seu vuitantèè aniversari, 221-269. Barcelona: Fundació Jaume I.

Ferrer i Mallol, M. a Teresa. 2003. «Bernat Vallès». En Història de la Generalitat de Catalunya i dels seus presidents, ed. Josep Maria Solé i Sabaté, vol 1, 61-66. Barcelona: Generalitat de Catalunya

Ferrer i Mallol, M. a Teresa. 2004. «Les Corts de Catalunya i la creació de la Diputació del General o Generalitat en el marc de la guerra amb Castella (1359-1369)». Anuario de Estudios Medievales 34 (2): 875-938. https://doi.org/10.3989/aem.2004.v34.i2.173

Ferrer i Mallol, M.a Teresa. 2005. «Els diputats del braçc de les ciutats i viles reials de 1359 a 1413: perfils biograàfics». Acta historica et archaeologica mediaevalia 26: 515-550.

Ferrer i Mallol, M. - Teresa. 2009. Els orígens de la Generalitat de Catalunya, 1359-1413. Barcelona: Generalitat de Catalunya.

Ferrer i Mallol, M. a Teresa y Josep Maria Roig Rosich, eds. 2011. Història de la Generalitat de Catalunya: dels orígens medievals a l'actualitat, 650 anys. Barcelona: Institut d'Estudis Catalans.
Franklin-Lyons, Adam. 2017. «Fourteenth-Century Rent Management in Catalonia: A Case Study of the Pia Almoina of Barcelona». Mediterranean studies 25: 229-267.

Gléenisson, Jean. 1947. «Un agent de la Chambre apostolique au XIVe siècle: les missions de Bartrand Bertrand du Mazel (1364-1378)». Mélanges d'archéologie et d'histoire de l'École française de Rome 59: 89-119.

González Reyes, Carlos. 2012. «Ascens polític, econòmic i reproducció social a la Catalunya baixmedieval. Els Planella de Moià». Porticum. Revista d'Estudis Medievals 4: 100-115.

Greiner, Lily. 1953. "Un représentant de la Chambre apostolique de Clément VII en Aragon au début du Grand Schisme (1378-1380)». Mélanges d'archéologie et d'histoire de l'École française de Rome 65: 197-213.

Jamme, Armand y Olivier Poncet. 2005. Offices, écrit et papauté (XIII $X V I{ }^{e}$ siècle): charges, hommes, destins. Rome: Ecole Française de Rome.

Jaspert, Nikolas. 1996. «Centro y periferia: los supervisores de la orden del Santo Sepulcro y sus prioratos en la Corona catalano-aragonesa». En La Orden del Santo Sepulcro. II Jordanas de Estudio (Zaragoza, 1995), 125-139. Zaragoza: Centro de Estudios de la Orden del Santo Sepulcro.

Laurent, Marie-Hyacinthe. ed. 1954-1985. Urbain V (1362-1370). Lettres communes analysées d'après les registres dits d'Avignon et du Vatican. 13 vols. Paris: Boccard.

Le Roux, Amandine. 2011. Servir le pape, le recrutement des collecteurs pontificaux dans le royaume de France et en Provence de la papauté d'Avignon à l'aube de la Renaissance (1316-1521). Tesis doctoral. Université de Paris.

López Pizcueta, Tomás. 1999. La Pia Almoina de Barcelona (11611350). Estudio de un patrimonio eclesiástico catalán bajomedieval. Barcelona: Fundación Noguera.

Lunt, William Edward. 1965. Papal Revenues in the Middle Ages. New York: Columbia University Press.

Mollat, Guillaume y Charles Saraman. 1905. La fiscalité pontificale en France au XIV siècle. Paris: Albert Fontemoing Editeur.

Montagut i Estragués, Tomàs. 1996. Les institucions fiscalitzadores de la Generalitat de Catalunya. Des dels seus origens fins a la reforma de 1413. Barcelona: Sindicatura de Comptes de Catalunya.

Morelló Baget, Jordi. 2001. Fiscalitat $i$ deute públic en dues viles de camp de Tarragona. Reus i Valls, segles XIV-XV. Barcelona: CSIC.

Morelló Baget, Jordi. 2009. "La maquinaría fiscal del papado aviñonés en la Corona de Aragón: la colectoría de Berenguer Ribalta (14001402)». Anuario de Estudios Medievales 39 (1): 65-125. https:// doi.org/10.3989/aem.2009.v39.i1.98

Morelló Baget, Jordi. 2012. «Andanzas (y malandanzas) de un colector pontificio en la Corona de Aragón: el caso de Folc Perer (13511371)». En En busca de Zaqueo: los recaudadores de impuestos en las épocas Medieval y Moderna, ed. Ángel Galán y Ernesto García, 175-193. Madrid: Instituto de Estudios Fiscales.

Morelló Baget, Jordi. 2013a. "La gestió comptable de la Cambra Apostólica al bisbat de Barcelona devers el 1390 (en temps del collector Guillem de Boudreville)». En A I'entorn de la Barcelona medieval. E: estudis dedicats a la Doctora Josefina Mutgé $i$ Vives, ed. Manuel Sánchez, 333-352. Barcelona: CSIC.

Morelló Baget, Jordi. 2013b. «El clero de Catalunya davant els impostos del General: a propòsit de la compravenda de draps al bisbat de Barcelona a la dècada de 1370». En Financiar el reino terrenal. La contribución de la Iglesia a finales de la Edad Media (siglos XIIIXVI), ed. Jordi Morell, 169-279. Barcelona: CSIC.

Morelló Baget, Jordi. 2013c. Financiar el reino terrenal: la contribución de la Iglesia a finales de la Edad Media (siglos XIII-XVI). Barcelona: CSIC.

Morelló Baget, Jordi. 2017. «En torno a la disyuntiva décima/subsidio en Castilla y la Corona de Aragón durante la Baja Edad Media». Hispania 77 (257): 643-671. https://doi.org/10.3989/hispania.2017.017

Morelló Baget, Jordi. 2018. «En defensa de la libertad eclesiástica. Actuación corporativa del clero de la Tarraconense y recaudación de tallas conciliares en los años que precedieron a la concordia de 1372». En Renda feudal i fiscalitat a la Catalunya baixmedieval: estudis dedicats a Manuel Sánchez Martínez, coord. Jordi Morelló, Pere Orti y Pere Verdés, 177-210. Barcelona: CSIC. 
Mutgé i Vives, Josefina. 2008. El monestir benedictí de Sant Pau del Camp de Barcelona, a través de la documentació de la cancelleria reial de l'Arxiu de la Corona d'Aragó (1287-1510). Barcelona: Fundació Noguera.

Nieto Soria, José Manuel y Jorge Díaz Ibáñez. 2001. «Élites y clientelas eclesiásticas en los siglos XIII al XV: una propuesta metodológica a partir del caso castellano». En Elite e redes clientelares na Idade Média: problemas metodológicos, (Évora, 15-16 de junio de 2000), dir. Filipe Themudo, 109-139. Lisboa: Colibri.

Orti Gost, Pere. 1999. «Una primera aproximació als fogatges catalans de la dècada de 1360». Anuario de Estudios Medievales 29: 747774. https://doi.org/10.3989/aem.1999.v29.i1.545

Reixach Sala, Albert. 2012. "Banqueros al servicio del poder: El cambista Ramon Medir de Gerona y la tesorería real durante la Guerra de los Dos Pedros (1356-1369)». En Comercio, banca y sociedad en los reinos hispánicos, siglos XIV-XVIII, en ed. Ángel Alloza Aparicio, Francisco Fernández Izquierdo y Elena García Guerra, 51-80. Madrid: Polifemo.

Renouard, Yves. 1941. Les relations des Papes d'Avignon et des Compagnies commerciales et bancaires de 1316 à 1378. Paris: de Boccard.

Riera i Melis, Antoni. 2011. "La Diputació del General de Catalunya, 1412-1458. Desenvolupament de les estructures i ampliació de les competències». En Història de la Generalitat de Catalunya: dels orígens medievals a l'actualitat, 650 anys, dir. M.. Teresa Ferrer, 43-72. Barcelona: Institut d'Estudis Catalans.

Ripoll Sastre, Pere. 2013. «The Deputation of the General of Catalonia: an overview of legal culture and institutional evolution». Glossae: European Journal of Legal History 10: 545-573

Ripoll Sastre, Pere. 2018. Llibre de vuit senyals (15th century): an edition, legal and comparative study. Tesis doctoral. Universitat Pompeu Fabra.

Sánchez Martínez, Manuel. 2005. «Negociación y fiscalidad en Cataluña a mediados del siglo XIV: las Cortes de Barcelona de 1365». En Negociar en la Edad Media, ed, María Teresa Ferrer, Jean-Marie Moeglin, Stéphane Péquignot y Manuel Sánchez, 123-164. BarceIona: CSIC.

Sánchez Martínez, Manuel. 2009. "Las primeras emisiones de deuda pública por la Diputación del General de Cataluña (1365-1369)». En La deuda pública en la Cataluña bajomedieval, ed. Manuel Sánchez, 219-258. Barcelona: CSIC.
Sánchez Martínez, Manuel. 2011. «La consolidaciò de la nova fiscalitat a Catalunya (1359-1380)». En Història de la Generalitat de Catalunya: dels orígens medievals a l'actualitat, 650 anys, dir. M. a Teresa Ferrer, 99-117. Barcelona: Institut d'Estudis Catalans.

Sánchez Martínez, Manuel, Antoni Furió y J. Ángel Sesma. 2008. «Old and New forms of taxation in the Crown of Aragon (13th-14th centuries) New Forms of Taxation». En La fiscalità nell'economia europea (sec. XIII-XVIII). 39 Settimana di Studi dell'Istituto Internazional di Storia Economica Francesco Datini (Prato, 2008), ed. Simonetta Cavaciocchi, 99-130. Firenze: Firenze University Press.

Sánchez Martínez, Manuel y Pere Orti Gost, eds. 1997. Corts, parlaments i fiscalitat a Catalunya. Els capitols del donatiu (1288-1384). Barcelona: Departament de Justícia de la Generalitat de Catalunya.

Serra i Puig, Eva. 2011. «La Generalitat. De les reformes del segle XV al creixement institucional del segle XVI». En Història de la Generalitat de Catalunya: dels orígens medievals a l'actualitat, 650 anys, dir. M. a Teresa Ferrer, 141-161. Barcelona: Institut d'Estudis Catalans.

Solé i Sabaté, Josep Maria, ed. 2003. Història de la Generalitat de Catalunya i dels seus presidents. Barcelona: Generalitat de Catalunya - Fundació Enciclopèdia Catalana.

Tello Hernández, Esther. 2020a. Pro defensione regni: Iglesia, monarquía y fiscalidad durante el reinado de Pedro IV (1349-1387). Madrid: CSIC.

Tello Hernández, Esther. 2020b. «Entre diplomacia y fiscalidad: el pago del censo de Cerdeña al papa durante el siglo XIV». En Diplomacia y desarrollo del Estado en la Corona de Aragón (siglos XIV-XVI), coord. Concepción Villanueva, 91-108. Gijón: Trea.

Torra Prat, Ricard. 2020. Anticorrupció i Pactisme. La Visita del General de Catalunya (1431-1714). Barcelona-Catarroja: Afers.

Trenchs i Òdena, José. 1971. La Cámara Apostólica y el reino de Aragón durante el pontificado de Benedicto XII. Tesis doctoral. Universidad de Barcelona.

Vincke, Johannes. 1932. "La Corona d'Aragó i el començament de les anualitats papals». Analecta sacra tarraconensia 8: 87-92.

Vones-Liebenstein, Ursula. 2005. «El método prosopográfico como punto de partida de la historiografía eclesiástica». Anuario de Historia de la Iglesia 14: 351-364.

VV. AA. 2007. Carreiras eclesiásticas no ocidente cristão: séc. XII-XIV. Lisboa: Universidade Católica Portuguesa - Centro de Estudos de História Religiosa. 